\title{
A Bread Bag Clip causing Small Bowel Perforation diagnosed on Computed Tomography
}

\author{
${ }^{1}$ Charles Coventry, ${ }^{2}$ Peter Bautz
}

\section{ABSTRACT}

Foreign body ingestion is common, and few result in complications. Plastic bread bag clips are an exception, however, and have been associated with small bowel perforation, upper gastrointestinal bleeding and even fatalities.

An 85 year-old woman presented with abdominal pain. She was found to have tenderness on abdominal palpation. She underwent an abdominal CT scan, which demonstrated a plastic bread bag clip as the cause of a contained small bowel perforation. A midline laparotomy and small bowel resection with primary anastomosis was performed.

Plastic bread bag clips are a rare cause of small bowel perforation. Elderly patients with dentures are at particular risk of ingesting such clips. This case report describes a rare situation where a clip is identified on preoperative imaging as the cause of a contained small bowel perforation.

Keywords: Plastic bread bag clip, Small bowel perforation.

How to cite this article: Coventry C, Bautz P. A Bread Bag Clip causing Small Bowel Perforation diagnosed on Computed Tomography. Panam J Trauma Crit Care Emerg Surg 2016;5(3):169-171.

\section{Source of support: Nil}

Conflict of interest: None

\section{RESUMEN}

La ingestion de cuerpos extranos es comun, pero ellos raramente inducen complicaciones. Las clips de bolsas de pan de plastico son excepsiones, porque han sido asociados con perforaciones del intestino delgado, sangrado del tracto gastrointestinal superior, y fatalidades.

Presentamos el caso de una mujer de 85 anos que llego' al hospital por un dolor abdominal. Ella tenia sensibilidad a la palpation del abdomen. Se realizo' TAC abdominal en el que se identifico' que una clip de bolsa de pan de plastico era la causa de una perforacion del intestino delgado. La perforacion se quedaba contenida. Se realizo' una laparotomia de la linea media y una recession del intestino delgado con una anastomosis primaria.

\footnotetext{
${ }^{1}$ Resident, ${ }^{2}$ Consultant

1,2Department of Surgery, Royal Adelaide Hospital, Adelaide South Australia, Australia
}

Corresponding Author: Charles Coventry, Resident, Department of Surgery, Royal Adelaide Hospital, Adelaide, South Australia Australia, Phone: +61882224000, e-mail: charles.coventry@ sa.gov.au
Las clips de bolsas de pan de plastico raramente causan perforaciones del intestino delgado. Los pacientes de edad avanzada con dentadura postiza tienen un riesgo aumentado de ingerir tal clips. En este caso describimos una rara situacion de una clip identificada con la imagen preoperatoria como la causa de una perforacion contenida del intestino delgado.

Palabras claves: Clip de bolsa de pan de plastico, Perforacion del intestino delgado.

\section{AIM}

To describe a rare case of small bowel perforation secondary to accidental ingestion of a plastic bread bag clip, which was diagnosed preoperatively on computed tomography (CT).

\section{INTRODUCTION}

Plastic bread bag clips are a common (and seemingly innocuous) household item which, if ingested, has been noted to result in a number of complications. As they are radiolucent on plain radiography, ${ }_{1}^{1}$ diagnosis on preoperative imaging is rare. This case report describes a rare situation where a bread bag clip was identified as a cause of contained small bowel perforation prior to operative management.

\section{CASE REPORT}

An 85-year-old woman with partial dentures presented to the emergency department of a tertiary hospital complaining of a 5-day history of colicky-type abdominal pain associated with nausea, vomiting, and occasional loose bowel motions, progressing to obstipation. There was no history of previous abdominal surgery and she denied ingestion of any inorganic foreign bodies. Examination revealed periumbilical tenderness on abdominal palpation. Laboratory tests revealed a mild leukocytosis and plain chest radiography was unremarkable, with no subphrenic gas demonstrated.

ACT scan of the abdomen and pelvis was performed, and this demonstrated stranding and small locules of gas surrounding the ileum consistent with a contained small bowel perforation. In addition, a foreign body clearly resembling a plastic bread bag clip was identified (Figs 1 to 3). This foreign body appeared to be the site of a small bowel obstruction, with dilation of bowel observed proximally and collapse observed distally. 


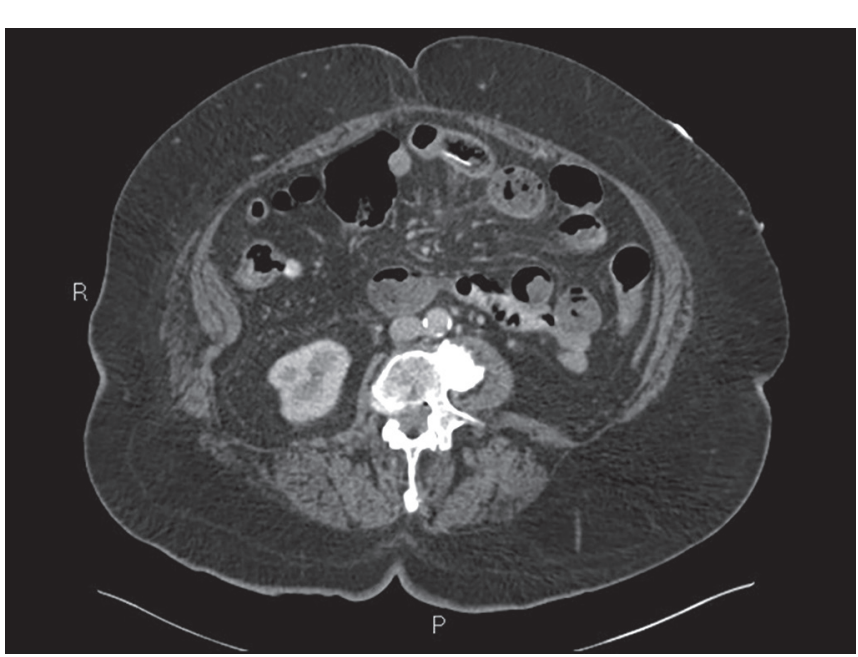

Fig. 1: Axial CT image demonstrating the bread bag clip and contained perforation

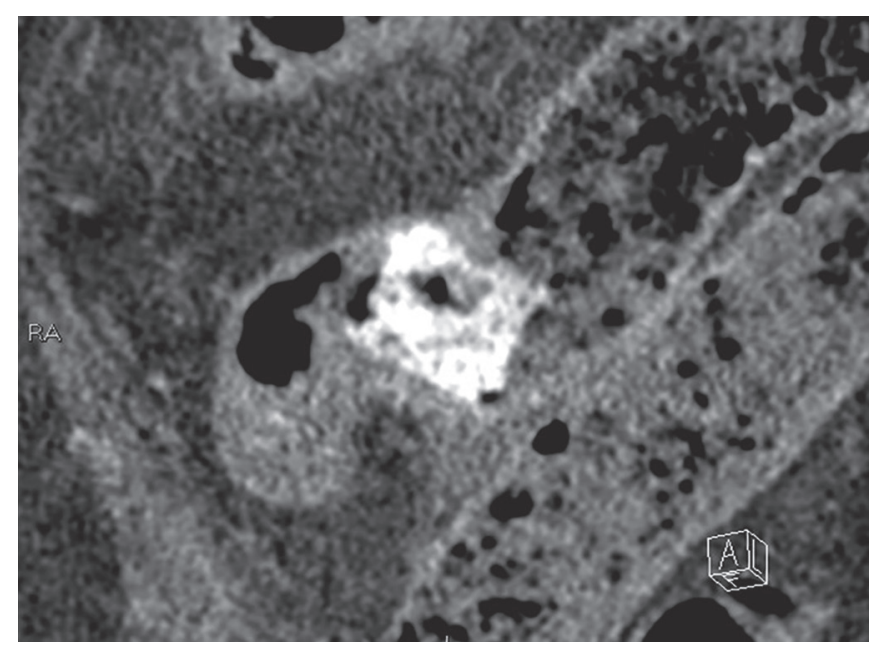

Fig. 2: Coronal CT image demonstrating the bread bag clip and contained perforation

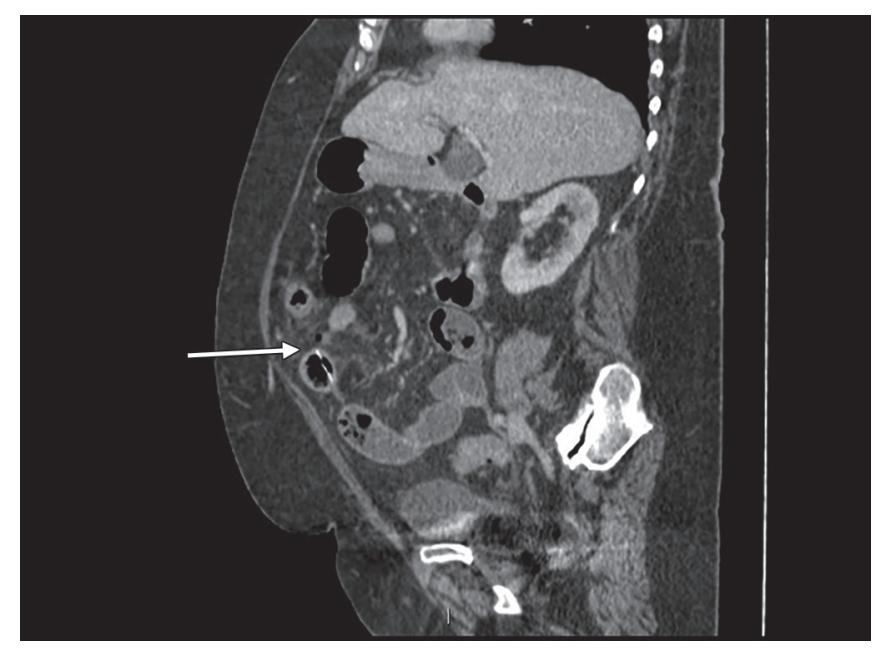

Fig. 3: A sagittal CT image demonstrating the bread bag clip (indicated by the arrow)

The patient was resuscitated, given intravenous antibiotics, and underwent laparotomy on the day of admission. A small bowel run was performed, demonstrating perforation of the bowel wall in the midileum at the site of the foreign body. A wedge resection of this perforated section of bowel was performed, along with primary ileoileal anastomosis.

Histology of the small bowel specimen demonstrated a plastic bread bag clip that was deeply impacted into the bowel wall, with surrounding mucosal ulceration. The patient was surprised to learn that a plastic bread bag clip was the cause of her symptoms, as she had no recollection of having ingested it. The rest of the patient's recovery was unremarkable, and she was discharged home.

\section{CONCLUSION}

The phenomenon of plastic bread bag clips causing perforation of the gastrointestinal tract has been well described in the literature, with case reports describing perforation and/or obstruction of the small bowel. ${ }^{2-4}$ Other reported complications include upper gastrointestinal hemorrhage. ${ }^{5}$ There are case reports in the literature of endoscopic retrieval of bread bag clips that are embedded in the mucosa of the duodenum., ${ }^{5,6}$ number of endoscopic instruments have been used for this improvised purpose, 5,6 but due to its relative infrequency, the choice of instrument remains up to the individual endoscopist. There have even been reports of fatalities from the complications of bread bag clip ingestion. 7,8

Plastic bread bag clips are thought to be particularly dangerous as small bowel mucosa becomes trapped between the sharp opposing edges, causing necrosis and eventual erosion through the small bowel wall. ${ }^{4}$ This potentially makes them more dangerous than other more commonly ingested plastic foreign bodies.

The elderly, especially those with partial or full dentures, are at particular risk of ingestion of bread bag clips ${ }^{9}$ and other potentially harmful foreign bodies. ${ }^{4,10}$ As in this case, patients with dentures are often unaware that they have ingested this foreign body. ${ }^{40}$ In addition, as plastic bread bag clips are radiolucent on plain radiograph, ${ }^{1}$ diagnosis is difficult. This case is unusual as a bread clip has been identified clearly on CT as the cause of the contained small bowel perforation on diagnostic imaging prior to laparotomy.

These difficulties in diagnosis, combined with an increasing number of documented cases, have led some medical professionals to call for redesign or replacement of these devices. ${ }^{2}$ This case is another example of why such opinions should be heard.

\section{CLINICAL SIGNIFICANCE}

This case illustrates why evidence of plastic bread bag clip ingestion should prompt vigilant observation for potential complications and demonstrates that plastic foreign bodies, such as bread bag clips, can be identified 
on $\mathrm{CT}$, aiding operative management. This is likely to become an increasing problem with the aging population in many regions.

\section{REFERENCES}

1. Lehmer LM, Ragsdale BD, Daniel J, Hayashi E, Kvalstad R. Plastic bag clip discovered in partial colectomy accompanying proposal for phylogenic plastic bag clip classification. BMJ Case Rep 2011 Jun 3;2011:pii. bcr0220113898.

2. Tang AP, Kong AB, Walsh D, Verma R. Small bowel perforation due to a plastic bread bag clip: the case for clip redesign. ANZ J Surg 2005 May;75(5):360-362.

3. Rivron RP, Jones DR. A hazard of modern life. Lancet 1983 Aug 6;2(8345):334.

4. Newell KJ, Taylor B, Walton JC, Tweedie EJ. Plastic bread-bag clips in the gastrointestinal tract: report of 5 cases and review of the literature. CMAJ 2000 Feb 22;162(4):527-529.
5. Ding NS, Ting AY, Loh D, Leong M, Hair C. Retrieval of a bread bag clip from the duodenum. Endoscopy 2013;45 (Suppl 2) UCTN:E309-E310.

6. Greenup AJ, Wright D, Koorey D. Gastrointestinal: Bread bag clip ingestion: cause for concern. J Gastroenterol Hepatol 2016 Feb;31(2):283.

7. Sutton G. Hidden dangers of sliced bread [letter]. Br Med J 1984 Jun 30;288(6435):1995.

8. Beer TW. Fatalities from bread tag ingestion. Med J Aust 2002 May 20;176(10):506.

9. Rodriguez-Hermosa JI, Codina-Cazador A, Sirvent JM, Martin A, Girones J, Garsot E. Surgically treated perforations of the gastrointestinal tract caused by ingested foreign bodies. Colorectal Dis 2008 Sep;10(7):701-707.

10. Chen Q, Huang Y, Wu Y, Zhao K, Zhu B, He T, Xing C. A comparative study of small intestinal perforation secondary to foreign body and other non-traumatic causes. Ulus Travma Acil Cerrahi Derg 2015 Mar;21(2):107-112. 